\title{
Syok Indeks dan Skor APACHE II pada Pasien yang Meninggal di GICU RSUP Dr. Hasan Sadikin Bandung Tahun 2016
}

\author{
Eka Damayanti, ${ }^{1}$ Indriasari, ${ }^{2}$ Iwan Fuadi $^{2}$ \\ ${ }^{1}$ Rumah Sakit Umum Daerah Serui, Papua, ${ }^{2}$ Departemen Anestesiologi dan Terapi Intensif \\ Fakultas Kedokteran Universitas Padjadjaran/RSUP Dr. Hasan Sadikin Bandung
}

\begin{abstract}
Abstrak
Sistem skoring untuk menilai prognosis dan mortalitas merupakan bagian penting dalam perawatan di General Intensive Care Unit (GICU). Sistem skoring yang lazim digunakan adalah acute physiological and chronic health evaluation (APACHE II), namun sistem ini memiliki kelemahan yang berkaitan dengan banyaknya variabel yang digunakan. Syok indeks (SI) merupakan modalitas yang baik untuk memprediksi mortalitas yang dibuktikan dalam beberapa penelitian baik di Instalasi Gawat Darurat (IGD) maupun GICU. Penelitian ini bertujuan mengetahui angka SI dan skor APACHE II pada pasien yang meninggal di GICU RSUP Dr. Hasan Sadikin Bandung periode Januari sampai Desember 2016. Penelitian dilakukan selama bulan Agustus 2017. Metode yang digunakan adalah deskriptif observasional retrospektif terhadap 198 subjek penelitian yang diambil di bagian rekam medis. Penelitian ini memperoleh angka SI berkisar 0,51-2,29 dengan median 1,08. Jumlah pasien dengan angka SI $<9$ sebanyak 27 pasien $(13,6 \%)$ dan SI $\geq 9$ sebanyak 171 pasien $(86,4 \%)$. Skor APACHE II berkisar 5-44 dengan median 28. Jumlah pasien dengan skor APACHE II $<25$ sebanyak 64 pasien (32,3\%), 25-35 sebanyak 114 pasien $(57,6 \%)$ dan $>35$ sebanyak 20 pasien $(10,1 \%)$. Lama perawatan yang lebih pendek didapatkan pada pasien dengan SI dan APACHE II yang tinggi mengindikasikan bahwa makin tinggi skor SI dan APACHE II makin tinggi pula angka mortalitas.
\end{abstract}

Kata kunci: Acute physiological and chronic health evaluation II, general intensive care unit, syok indeks

\section{Shock Index and APACHE II Score in Patients Died at GICU ofDr. Hasan Sadikin Bandung General Hospital in 2016}

\begin{abstract}
The prognostic and predictive mortality scoring system is an important part of the care at General Intensive Care Unit (GICU). The scoring system that is commonly used today is acute physiological and chronic health evaluation (APACHE II); however, this scoring system has a disadvantage in relation to the number of variables used. Therefore, a more practical assessment system is needed. Shock Index (SI) is a good modality for predicting mortality and has been demonstrated in several studies conducted in both Emergency Department (ED) and GICU. The purpose of this study was to describe the SI and APACHE II scores in patients who died at the GICU of Dr. Hasan Sadikin Bandung during January to December 2016. This was a descriptive observational study with retrospective approach on 198 medical records. Data collection was performed in August 2017. The SI results in this study ranged from 0.51-2.29 with a median of 1.08. The number of patients with SI of $<9$ and SI of $\geq 9$ were 27 (13.6\%) and 171 (86.4\%), respectively. The APACHE II scores ranged from 5 to 44 with a median of 28 . The number of patients with APACHE II score of $<25,25-35$, and $>35$ were $64(32.3 \%), 114(57.6 \%)$, and $20(10.1 \%)$, respectively. Shorter duration of treatment found in patients with higher SI and APACHE II, indicating that higher SI and APACHE II scores relate to higher mortality.
\end{abstract}

Key words: Acute physiological and chronic health evaluation II, general intensive care unit, shock index

Korespondensi: Eka Damayanti, dr., SpAn, Rumah Sakit Umum Daerah Serui, Papua, Jl. Dr Samratulangi Serui, Waropen, Papua, Indonesia, Tlpn 0983-31132, Email myshasa17@gmail.com 


\section{Pendahuluan}

Pemilihan sistem skoring untuk menentukan prognosis dan memprediksi mortalitas merupakan bagian penting dalam perawatan di General Intensive Care Unit (GICU) karena kesalahan pemilihan dan penggunaan sistem skoring dapat membuang waktu, meningkatkan biaya, dan dapat mengacu pada keputusan yang kurang tepat. ${ }^{1,2}$ Sistem skoring yang tersedia dan lazim digunakan saat ini adalah acute physiological and chronic health evaluation (APACHE II), namun sistem skoring ini memiliki kelemahan dari segi biaya dan kepraktisan penggunaan berkaitan dengan banyaknya variabel yang digunakan. APACHE II dan III memerlukan banyak data yang dikumpulkan atau diambil setelah lebih dari 24 jam bergantung pada kualitas pelayanan dari GICU. Selain itu, pengumpulan data dari 12 variabel pada lebih dari 24 jam pertama sulit dilakukan dan sering kali data dikumpulkan secara tidak akurat. ${ }^{1-3}$

Salah satu sistem skoring yang mudah dan praktis untuk memprediksi mortalitas pada pasien kritis adalah syok indeks (SI). Syok indeks (SI) merupakan sistem penilaian bedside yang didapatkan dari hasil bagi denyut jantung dibagi dengan tekanan darah sistole, dengan nilai normal 0,5-0,7. Sistem skoring ini menjadi penanda prognosis yang baik pada pasien trauma dan berhubungan dengan mortalitas pada pasien dengan penyakit kritis. $^{4-6}$

Penggunaan SI di unit gawat darurat sangat baik untuk memprediksi prognosis dan mortalitas pasien dengan trauma multipel, penyakit kritis akut, pengenalan dini sepsis, serta penempatan pasien di unit perawatan intensif (GICU) yang tidak direncanakan sebelumnya. Penelitian di Kolombia menemukan bahwa SI $\geq 0,9$ dapat memprediksi mortalitas yang lebih baik yang diakibatkan penyakit tertentu sehingga berhubungan dengan lama perawatan di rumah sakit jika dibanding dengan hanya pemeriksaan nadi atau tekanan darah. Hal ini menunjukkan bahwa SI dapat dijadikan alat yang berguna untuk mengenali dan mengevaluasi penyakit kritis secara dini di IGD dan dapat pula digunakan untuk menilai kemajuan/hasil resusitasi. Penelitian tersebut telah mengevaluasi kegunaan SI dan menunjukkan bahwa cut-of point $\geq 0,9$ akurat untuk memprediksi mortalitas pada pasien sakit kritis. ${ }^{5,7,8}$

Berbagai penelitian yang sudah dilakukan menyimpulkan SI merupakan modalitas efektif dan tanpa biaya untuk menilai pasien dengan risiko sepsis dan juga untuk memprediksi mortalitas 28 hari. Syok Indeks juga dapat diaplikasikan secara luas di rumah sakit lain karena pengukurannya yang cepat dan aplikatif. Penggunaan SI selain untuk memprediksi mortalitas juga dapat digunakan sebagai penanda prognosis pasien GICU dan dapat memprediksi instabilitas hemodinamik di masa yang akan datang., ${ }^{4,7}$

Tujuan penelitian ini adalah mengetahui angka syok indeks dan skor APACHE II pada pasien yang meninggal di GICU RSUP Dr. Hasan Sadikin Bandung periode Januari sampai dengan Desember 2016.

\section{Subjek dan Metode}

Penelitian ini merupakan penelitian deskriptif observasional yang dilakukan secara retrospektif mengenai angka syok indeks dan skor APACHE II pada pasien yang meninggal di GICU RSUP Dr. Hasan Sadikin Bandung periode Januari sampai dengan Desember 2016. Penelitian dilakukan pada bulan Agustus 2017. Subjek penelitian ini adalah rekam medis pasien yang meninggal dalam perawatan di GICU Rumah Sakit Dr. Hasan Sadikin Bandung yang memenuhi kriteria inklusi dan tidak termasuk kriteria eksklusi.

Kriteria inklusi pada penelitian ini adalah pasien berusia di atas 15 tahun yang meninggal dalam perawatan di GICU RSUP Dr. Hasan Sadikin Bandung. Kriteria eksklusi pada penelitian ini adalah pasien yang sedang menjalani terapi yang dengan efek blokade atrioventrikular seperti: $\beta$-blocker, Ca-channel blocker, digoksin, dan amiodaron dan pasien pulang paksa dalam waktu kurang dari 28 hari. Kriteria pengeluaran pada penelitian 
ini adalah data yang tidak lengkap dan skor APACHE yang tidak dihitung.

Pengumpulan data secara keseluruhan dilakukan sejak disetujui oleh Komite Etik Penelitian Kesehatan Fakultas Kedokteran Universitas Padjadjaran/RSHS pada bulan Agustus 2017 menggunakan data rekam medis pasien yang meninggal di GICU pada periode Januari sampai dengan Desember 2016. Data yang diambil adalah usia, jenis kelamin, tindakan surgical atau non surgical, angka syok indeks, skor APACHE II, lama perawatan sampai pasien meninggal di GICU (length of stay/LOS). Data kategorik dideskripsikan dengan distribusi frekuensi dan proporsi, sedangkan untuk data numerik seperti usia dideskripsikan dalam bentuk ukuran pemusatan dan penyebaran data numerik.

Analisis data digunakan untuk mengetahui karakteristik pasien yang meninggal di GICU. Deskripsi karakteristik dan status pasien ditampilkan dalam bentuk tabel. Data kategorik dideskripsikan dengan jumlah (n) dan persentase (\%). Data numerik dideskripsikan dalam bentuk rata-rata, standar deviasi (SD), median, dan rentang (minimal-maksimal).

\section{Hasil}

Total terdapat 198 pasien yang dioperasi selama penelitian ini. Kelompok usia terbanyak 18-65 tahun (92,9\%). Jenis kelamin laki-laki lebih banyak daripada perempuan (53,5\%). Tekanan darah sistole rata-rata sebesar 120,20 $\pm 13,7 \mathrm{mmHg}$, tekanan darah diastole sebesar 75,10 $\pm 12,63 \mathrm{mmHg}$ dan laju nadi median sebesar 129 kali/menit. Sebagian besar pasien merupakan pasien bedah atau surgical. Dari semua subjek penelitian, $86,4 \%$ pasien dengan $\mathrm{SI} \geq 0,9$ dan $57,6 \%$ pasien dengan skor APACHE II 25-35 (Tabel 1). Penghitungan Syok Indeks dan APACHE II pada penelitian ini memiliki median 1,08 dan 28,00 (Tabel 2).

Usia median pada pasien dengan SI $\geq 0,9$, yaitu 53 tahun dan pasien dengan SI $<0,9$ adalah 50 tahun. Lama perawatan pada pasien dengan $S I \geq 0,9$ lebih pendek dibanding dengan pasien dengan $\mathrm{SI}<0,9$ (Tabel 3). Pasien dengan skor APACHE II yang lebih tinggi memiliki usia
Tabel 1 Karakteristik Umum Pasien

\begin{tabular}{|c|c|}
\hline Variabel & $n=198$ \\
\hline \multicolumn{2}{|l|}{ Usia (tahun/\%) } \\
\hline$<18$ & $2(1,0)$ \\
\hline $18-65$ & $184(92,9)$ \\
\hline$>65$ & $12(6,1)$ \\
\hline \multicolumn{2}{|l|}{ Jenis kelamin $(\mathrm{n} ; \%)$} \\
\hline Laki-laki & $106(53,5)$ \\
\hline Perempuan & $92(46,5)$ \\
\hline \multicolumn{2}{|c|}{ Tekanan darah sistole (mmHg) } \\
\hline Mean $\pm \mathrm{SD}$ & $120,20 \pm 13,72$ \\
\hline Median & 119,00 \\
\hline Range (min.-maks.) & $56,00-169,00$ \\
\hline \multicolumn{2}{|c|}{ Tekanan darah diastole (mmHg) } \\
\hline Mean $\pm \mathrm{SD}$ & $75,10 \pm 12,633$ \\
\hline Median & 76,00 \\
\hline Range (min.--maks.) & $34,00-100,00$ \\
\hline \multicolumn{2}{|l|}{ Laju nadi (kali/menit) } \\
\hline Median & 129,00 \\
\hline Range (min.-maks.) & $69,00-158,00$ \\
\hline \multicolumn{2}{|c|}{ Surgical/non surgical (n;\%) } \\
\hline Surgical & $135(68,7)$ \\
\hline $\begin{array}{l}\text { Elektif } \\
\text { Emergensi } \\
\text { Non surgical }\end{array}$ & $\begin{array}{c}24(17,2) \\
111(82,2) \\
63(31,3)\end{array}$ \\
\hline \multicolumn{2}{|l|}{ Syok indeks (n;\%) } \\
\hline$<0,9$ & $27(13,6)$ \\
\hline$\geq 0,9$ & $171(86,4)$ \\
\hline \multicolumn{2}{|l|}{ Skor APACHE II (n;\%) } \\
\hline$<25$ & $64(32,3)$ \\
\hline $25-35$ & $114(57,6)$ \\
\hline$>35$ & $20(10,1)$ \\
\hline
\end{tabular}

Keterangan: untuk data kategorik disajikan dengan jumlah/frekuensi dan persentase, sedangkan data numerik disajikan dengan rata-rata, median, standar deviasi, dan range

rata-rata yang lebih tinggi. Lama perawatan pada pasien dengan skor APACHE <25 lebih panjang dibanding dengan pasien dengan skor APACHE II lainnya. Lama perawatan pasien pada skor APACHE II 25-35 dan skor APACHE >35 masing-masing memiliki rata- 
Tabel 2 Gambaran Syok Indeks dan Skor APACHE II

\begin{tabular}{lc}
\hline \multicolumn{1}{c}{ Variabel } & $\mathbf{n = 1 9 8}$ \\
\hline Syok Indeks & 1,08 \\
Median & $0,51-2,29$ \\
Range (min.-maks.) & 28,00 \\
Skor APACHE II & $5,00-44,00$ \\
Median & \\
Range (min.-maks.) & \\
\hline Keterangan: & data kategorik disajikan dengan jumlah/ \\
& frekuensi dan persentase, sedangkan data \\
& numerik disajikan dengan rata-rata, median, \\
& standar deviasi, dan range
\end{tabular}

rata 5,50 $\pm 4,39$ dan 5,15 $\pm 3,21$ hari (Tabel 5). Terdapat 63 pasien yang mendapatkan obatobatan vasoaktif pada hari pertama memiliki median $\mathrm{SI}=1,125$ dan pada hari kedua dan seterusnya memiliki median SI=1,056 (Tabel $5)$.

\section{Pembahasan}

Pada penelitian ini didapatkan bahwa dari 198 subjek penelitian yang meninggal selama perawatan di GICU RSUP Dr. Hasan Sadikin Bandung Periode Januari-Desember 2016, mayoritas berusia 18-65 tahun (92,9\%). Pada penelitian-penelitian sebelumnya dinyatakan hal yang berbeda. Usia masih merupakan faktor yang memengaruhi mortalitas pada pasien kritis. Sebuah penelitan pada tahun 2010 terhadap 351 pasien GICU yang dirawat dengan diagnosis pneumonia dinyatakan bahwa peningkatan usia berhubungan dengan mortalitas jangka pendek maupun jangka panjang, peningkatan mortalitas terjadi pada usia di atas 60 tahun. ${ }^{9}$

Pada penelitian selanjutnya yang dilakukan di Taiwan pada tahun 2014-2015 terhadap 254 pasien yang dirawat di GICU dengan sepsis berat, didapatkan angka mortalitas antara pasien usia di bawah 65 tahun dan di atas 65 tahun tidak berbeda secara signifikan. ${ }^{10}$ Perbedaan antara hasil penelitian ini dan penelitian sebelumnya mungkin disebabkan oleh jumlah sampel yang lebih sedikit.

Perbandingan jenis kelamin pada penelitian ini adalah laki-laki $(53,5 \%)$ dan perempuan $(46,5 \%)$. Penelitian sebelumnya terhadap 261.255 pasien yang dirawat di GICU dinyatakan bahwa wanita dengan usia $<50$ tahun memiliki angka mortalitas yang lebih rendah dibanding dengan pria. Namun, wanita dengan usia di atas 50 tahun memiliki angka mortalitas yang sama dengan pria. Peningkatan mortalitas terjadi pada pasien yang dirawat di GICU karena CABG dan tidak ada perbedaan angka mortalitas antara pria dan wanita dengan sindrom koroner akut, sepsis, dan trauma. ${ }^{11}$

Pasien yang meninggal pada penelitian ini

Tabel 3 Gambaran Syok Indeks berdasar atas Usia dan Lama Perawatan

\begin{tabular}{lcc}
\hline \multirow{2}{*}{ Variabel } & Syok Indeks $<\mathbf{0 , 9}$ & Syok Indeks $\geq \mathbf{0 , 9}$ \\
\cline { 2 - 3 } & $\mathbf{n = 2 7}$ & $\mathbf{n = 1 7 1}$ \\
\hline Usia (tahun) & & \\
Mean \pm SD & $51,07 \pm 13,91$ & $48,40 \pm 14,92$ \\
Median & 53,00 & 50,00 \\
Range (min.-maks.) & $17,00-78,00$ & $15,00-82,00$ \\
Lama perawatan (hari) & & \\
Mean \pm SD & $8,25 \pm 5,97$ & $6,17 \pm 4,98$ \\
Median & 7,00 & 5,00 \\
Range (min.-maks.) & $1,00-26,00$ & $1,00-27,00$ \\
\hline
\end{tabular}

Keterangan: data kategorik disajikan dengan jumlah/frekuensi dan persentase, sedangkan data numerik disajikan dengan rata-rata, median, standar deviasi, dan range 
Tabel 4 Gambaran Skor APACHE II berdasar atas Usia dan Lama Perawatan

\begin{tabular}{|c|c|c|c|}
\hline \multirow{3}{*}{ Variabel } & \multicolumn{3}{|c|}{ Skor APACHE II } \\
\hline & $<25$ & $25-35$ & $>35$ \\
\hline & $n=64$ & $n=114$ & $\mathbf{n}=\mathbf{2 0}$ \\
\hline \multicolumn{4}{|l|}{ Usia (tahun) } \\
\hline$M e a n \pm \mathrm{SD}$ & $43,29 \pm 14,03$ & $50,50 \pm 14,34$ & $56,35 \pm 14,47$ \\
\hline Median & 44,50 & 53,00 & 62,00 \\
\hline Range (min.-maks.) & $15,00-78,00$ & $18,00-82,00$ & $19,00-80,00$ \\
\hline \multicolumn{4}{|l|}{ Lama perawatan (hari) } \\
\hline Mean \pm SD & $8,57 \pm 6,23$ & $5,50 \pm 4.39$ & $5,15 \pm 3,21$ \\
\hline Median & 6,50 & 4,00 & 5,00 \\
\hline Range (min.-maks.) & $1,00-27,00$ & $1,00-24,00$ & $1,00-12,00$ \\
\hline
\end{tabular}

Keterangan: data kategorik disajikan dengan jumlah/frekuensi dan persentase, sedangkan data numerik disajikan dengan rata-rata, median, standar deviasi, dan range

sebagian besar merupakan pasien bedah atau surgikal (68,2\%). Pada penilaian skor APACHE II, pasien yang mendapatkan intervensi pembedahan nonemergensi diberikan nilai 2 dengan nilai lebih kecil dibanding dengan nilai yang diberikan pada pasien nonsurgikal ataupun pasien yang menjalani operasi emergensi. ${ }^{12}$

Hal ini menggambarkan bahwa pasien yang menjalani pembedahan memiliki risiko mortalitas yang sama pada pembedahan emergensi dan sebaliknya lebih rendah pada pembedahan elektif. Angka mortalitas pasien surgikal lebih tingi pada penelitian ini disebabkan oleh jenis pembedahan yang bersifat emergensi karena pada pembedahan emergensi pasien dalam kondisi yang mungkin tidak optimal. Selain itu, dapat pula dipengaruhi oleh komplikasi setelah pembedahan, seperti infeksi dan sebagainya. Diperlukan data yang lebih lengkap untuk menilai apakah komplikasi pembedahan memperberat keadaan pasien atau tidak.

Sebanyak 171 pasien dari 198 pasien $(86,4 \%)$ pasien memiliki SI $\geq 0,9$. Hal ini sesuai dengan penelitian sebelumnya di tahun 2010 pada 50 pasien yang masuk ke GICU dan menyatakan $\mathrm{SI}>0,85$ berhubungan dengan tingginya angka perawatan di GICU. Beberapa penelitian lain menyatakan bahwa nilai $S I \geq 0,9$ dapat dijadikan cut-off untuk memprediksi mortalitas pada pasien yang sakit kritis. Namun, penelitian lain menyatakan bahwa SI $>0,7$ berkaitan dengan kebutuhan penggunaan vasopresor dan peningkatan angka mortalitas pada pasien di GICU. Perbedaan ini dapat diakibatkan oleh jumlah sampel yang lebih banyak pada penelitian sebelumnya, yaitu

Tabel 5 Gambaran Syok Indeks berdasar atas Penggunaan Obat-obatan Vasoaktif

\begin{tabular}{lcc}
\hline \multirow{2}{*}{ Syok Indeks } & \multicolumn{2}{c}{ Penggunaan Obat-obatan Vasoaktif } \\
\cline { 2 - 3 } & Hari Pertama & Hari Kedua-dst. \\
& $\mathbf{n}=\mathbf{6 3}$ & $\mathbf{n = 1 3 5}$ \\
\hline Mean \pm Std & $1,13 \pm 0,235$ & $1,03 \pm 0,152$ \\
Median & 1,125 & 1,056 \\
Range (min.-maks.) & $0,51-2,29$ & $0,60-1,38$ \\
\hline
\end{tabular}

Keterangan: data kategorik disajikan dengan jumlah/frekuensi dan persentase, sedangkan data numerik disajikan dengan rata-rata, median, standar deviasi, dan range 


\subsection{0 orang., ${ }^{4,13,14}$}

Pada penelitian ini didapatkan bahwa lama perawatan di GICU lebih pendek pada pasien dengan $S I \geq 0,9$, yaitu lama rawat ratarata $6,17 \pm 4,98$. Hal tersebut disebabkan oleh prognosis yang lebih buruk pada pasien dengan SI yang lebih tinggi. Selain penilaian SI, skor APACHE II pada penelitian ini dinyatakan bahwa mortalitas terjadi paling banyak pada skor APACHE II 25-35, yaitu sebanyak 114 pasien $(57,6 \%)$, sedangkan mortalitas paling sedikit pada skor APACHE II >35 sebanyak 20 pasien $(10,1 \%)$. Hal ini tidak sesuai dengan penelitian sebelumnya bahwa peningkatan APACHE II berhubungan dengan peningkatan angka mortalitas.

Penelitian di Pakistan pada tahun 2011 dinyatakan korelasi yang baik antara mortalitas yang diprediksi dan mortalitas yang diamati, namun menggambarkan overestimasi pada sistem APACHE II. APACHE II dinilai memiliki kekuatan diskriminasi yang baik untuk memisahkan pasien yang selamat dari pasien yang meninggal, namun kurang sensitif, spesifik, dan akurat untuk memprediksi mortalitas pasien secara tepat dan individual. ${ }^{15}$

Penelitian lain di Iran tahun 2013 memberikan hasil yang serupa, yaitu peningkatan skor APACHE II sebanding dengan risiko mortalitas, namun kekuatan diskriminasi dan kapasitas prediktif skor ini sedang. Perbedaan ini mungkin disebabkan oleh penilaian APACHE II yang kurang akurat ataupun perbedaan jumlah sampel pada penelitian ini yang lebih sedikit. ${ }^{16}$

Pada penelitian ini didapatkan bahwa usia yang lebih tinggi berhubungan dengan skor APACHE II yang lebih tinggi. Hal tersebut disebabkan oleh parameter usia yang merupakan salah satu poin yang dinilai dalam APACHE II. Lama perawatan juga dapat dihubungkan dengan pasien dengan jumlah skor APACHE II yang lebih tinggi. Pasien dengan skor APACHE II $<25$ memiliki lama perawatan lebih panjang sekitar $8,57 \pm 6,23$ dibanding dengan pasien skor APACHE II 25-35 sekitar 5,50 $\pm 4,93$ dan >35 sekitar $5,15 \pm 3,21$. Hal ini menggambarkan bahwa makin tinggi skor APACHE II maka makin buruk luaran pasien dan makin tinggi pula angka mortalitas, tetapi lama perawatan pada pasien dengan skor APACHE II 25-35 dan skor APACHE II >35 tidak ada perbedaan. Hal ini tidak sesuai dengan penelitian sebelumnya yang menyatakan bahwa skor APACHE II yang lebih dari 25 dapat memprediksi mortalitas sebesar 50\% dan skor APACHE II lebih dari 35 dapat memprediksi mortalitas sebesar 80\% sehingga lama perawatan di GICU menjadi lebih pendek. $^{1,12} \mathrm{Hal}$ ini mungkin disebabkan oleh pasien dengan APACHE $>35$ sudah meninggal sebelum dirawat di GICU karena waktu antara pasien masuk hingga transfer ke GICU tidak dapat diprediksi akibat keterbatasan fasilitas.

Obat-obatan vasoaktif telah digunakan untuk menangani perubahan hemodinamik yang berhubungan dengan syok selama lebih dari 40 tahun. Obat-obatan tersebut digunakan untuk memanipulasi distribusi aliran darah relatif dan mengembalikan perfusi jaringan. Obat-obatan vasoaktif dapat dibagi menjadi dua kelas, yaitu vasopresor dan inotrop. Keduanya berfungsi melalui stimulasi reseptor adrenergik atau simpatomimetik. . $^{17,18}$ Walaupun obat-obat vasoaktif secara, efektif meningkatkan performa kardiak dan parameter hemodinamik, obat-obatan tersebut juga memiliki efek samping seperti aritmia, peningkatan konsumsi oksigen miokardial, iskemia miokardium, dan perubahan metabolik. ${ }^{17}$

Beberapa penelitian menyatakan bahwa penggunaan obat-obatan vasoaktif berhubungan dengan peningkatan mortalitas. ${ }^{17}$ Penelitian ini terdapat 63 pasien yang telah mendapatkan obat-obatan vasoaktif di hari pertama dengan angka syok indeks di median 1,125 , sedangkan sebanyak 135 pasien yang mendapatkan obat-obatan vasoaktif di hari kedua dan seterusnya dengan angka syok indeks di median 1,056. Penggunaan vasoaktif di hari pertama berhubungan dengan syok indeks yang lebih tinggi dibanding dengan penggunaan syok indeks di hari kedua dan seterusnya.

Sebuah penelitian meta-analisis yang dilakukan pada tahun 2015 terhadap 28.280 
pasien dalam 177 penelitian memperlihatkan tidak ada perbedaan mortalitas antara kelompok yang menggunakan obat vasoaktif dan kelompok kontrol $(\mathrm{p}=0,23)$. Penurunan mortalitas terjadi berhubungan dengan penggunaan vasopresor pada sindrom vasoplegik, sepsis dan operasi kardiak, namun tidak signifikan secara statistik. Analisis subkelompok tidak mengidentifikasi kelompok dengan peningkatan mortalitas yang berhubungan dengan penggunaan obat vasoaktif. ${ }^{17}$ Pada penelitian ini mortalitas terjadi lebih banyak pada pasien dengan penggunaan vasoaktif. Hal ini mungkin disebabkan oleh perbedaan protokol pemberian vasoaktif ataupun perbedaan jumlah sampel. Sampel pada penelitian ini lebih sedikit.

Keterbatasan penelitianiniadalah penilaian syok indeks dilakukan hanya satu kali, yaitu saat pasien masuk GICU. Sebuah penelitian dilakukan pada tahun 2015 terhadap 66 pasien yang dirawat di GICU tersier di Amerika Serikat. Pada penelitian tersebut dilakukan penilaian syok indeks secara berkala dan dapat disimpulkan bahwa mortalitas paling banyak terjadi pada kelompok pasien dengan peningkatan syok indeks yang terus menerus akibat kerusakan organ yang lebih banyak. Penilaian skor APACHE II dan penggunaan kronotropik juga dilakukan pada kedua kelompok dan didapatkan tidak terdapat perbedaan signifikan secara statistik. Hal ini mungkin dapat dilakukan pada penelitian selanjutnya dengan melakukan penilaian Syok Indeks berkala pada jumlah sampel yang lebih banyak untuk menilai hubungan antara peningkatan Syok Indeks dan mortalitas.

\section{Simpulan}

Simpulan pada penelitian ini adalah mortalitas terjadi paling banyak pada $\mathrm{SI} \geq 0,9$ dan skor APACHE II antara 25-35. Lama perawatan yang pendek di GICU berhubungan dengan nilai SI dan APACHE II yang lebih tinggi, hal ini menggambarkan bahwa makin tinggi nilai SI dan APACHE II, makin buruk luaran pasien dan makin tinggi angka mortalitasnya.

\section{Daftar Pustaka}

1. Bouch C, Thompson JP. Severity scoring systems in the critically ill. Cont Educ Anaesth Crit Care Pain. 2008;8(5):181-5.

2. Moreno R, Metnitz P. Scoring systems and outcome. Dalam: Gulo A, Lumb PD, penyunting. Intensive and critical care medicine reflections, recommendations and perspective. Edisi ke-2. Trieste: Springer; 2005. hlm. 117-30.

3. Taofik S, Subagiartha IM, Senapathi TGA. Perbandingan validitas sistem skoring acute physiological chronic health evaluation II, sequential organ failure assessment untuk memperkirakan mortalitas pasien non-bedah yang dirawat di ruang perawatan intensif. JKI. 2015;46(3):145-51.

4. Zampieri F, Colombari F. Use of shock index as a prognostic marker in patients with normal heart rate and blood pressure at ICU admission. Intens Care Med Exp. 2015;3(Suppl 1):A596.

5. Berger T, Green J, Horeczko T, Hagar Y, Garg N, Suarez A, dkk. Shock index and early recognition of sepsis in the emergency department: Pilot Study. West J Emerg Med. 2013;15(2):168-74.

6. Balhara K, Hsieh Y, Hamade B. Clinical metrics in emergency medicine: the shock index and the probability of hospital admission and inpatient mortality. Emerg Med J. 2017;34(1):89-94.

7. Montoya KF, Charry JD, Calle-Toro JS, Nuñez LR, Poveda1 G. Shock index as a mortality predictor in patients with acute polytrauma. J Acute Dis. 2015;4(3):202-4.

8. Smischney NJ, Seisa MO, Heise KJ, Schroeder DR, Weister TJ, Diedrich DA. Elevated modified shock index within 24 hours of icu admission is an early indicator of mortality in the critically ill. J Intens Care Med. 2016;1(1):1-7.

9. Sligl WI, Eurich DT, Marrie TJ, Majumdar SR. Age still matters: prognosticating shortand long-term mortality for critically ill patients with pneumonia. Crit Care Med. 2010;38(11):2126-32. 
10. Chen C-M, Cheng K-C, Chan K-S, Yu WL. Age may not infl uence the outcome of patients with severe sepsis in intensive care units. Int J Gerontol. 2014;8(1):22-6.

11. Mahmood K, Eldeirawi K, Wahidi MM. Association of gender with outcomes in critically ill patients. Crit Care. 2012;16(1):R92-101.

12. Rapsang AG, Shyam DC. Scoring systems in the intensive care unit: a compendium. Indian J Crit Care Med. 2014;18(4):220-8.

13. Keller AS, Kirkland LL, Rajasekaran SY, Cha S, Rady MY, Huddleston JM. Unplanned transfers to the intensive care unit: the role of the shock index. J Hosp Med. 2010;5(1):460-5.

14. Saleh A, Ahmed M, Sultan I, Abdel-lateif A. Comparison of the mortality prediction of different ICU scoring systems (APACHE II and III, SAPS II, and SOFA) in a singlecenter ICU subpopulation with acute respiratory distress syndrome. Egypt J Chest Dis Tuberc. 2015(64):838-48.

15. Naved SA, Siddiqui S, Khan FH. APACHEII score correlation with mortality and length of stay in an Intensive Care Unit. J Coll Physicians Surg Pak. 2011;21(1):4-8.

16. Mahdaviazad $H$, Imanieh $M$, Masoompour S. Effectiveness of the APACHE II scoring system in an intensive care unit: results of a prospective study. Br J Med Med Res. 2015;8(12):1-14.

17. Belletti A, Castro ML, Silvetti1 S, Greco1 T, Biondi-Zoccai G, Pasin L, dkk. The effect of inotropes and vasopressors on mortality:a meta-analysis of randomized clinical trial. Br J Anaesth. 2015;115(5):656-75.

18. Ellender TJ, Skinner JC. The use of vasopressors and inotropes in the emergency medical treatment of shock. Emerg Med Clin N Am. 2008;26:759-86. 